\title{
Pemanfaatan Dana Kapitasi oleh Puskesmas di Kota Lubuklinggau Tahun 2014-2016
}

\author{
Capitation Utilization by Public Health Care in Lubuklinggau City \\ in 2014-2016 \\ Muhammad Yulianto ${ }^{1}$, Mardiati Nadjib² \\ ${ }^{1}$ Program Studi Magister Ilmu Kesehatan Masyarakat Fakultas Kesehatan Masyarakat Universitas Indonesia, Depok \\ ${ }^{2}$ Departemen Administrasi Kebijakan Kesehatan, Fakultas Kesehatan Masyarakat, Universitas Indonesia, Depok \\ Korespondensi: Muhammad Yulianto \\ e-mail:antoskm84@yahoo.co.id
}

\begin{abstract}
Abstrak
Sejak implementasi Jaminan Kesehatan Nasional (JKN), Puskesmas mendapat pembayaran dari Badan Penyelenggaran Jaminan Sosial (BPJS) Kesehatan berupa dana kapitasi. Di Kota Lubuklinggau terdapat masalah mengenai sisa lebih perhitungan anggaran (SiLPA) di puskesmas yang rata-rata pertahunnya sebesar 23\%. Penelitian ini bertujuan menganalisis pemanfaatan dana kapitasi Puskesmas di Kota Lubuklinggau tahun 2014-2016. Penelitian kualitatif ini dilakukan di Puskesmas Simpang Periuk, Taba, Citra Medika dan Swasti Saba berdasarkan realisasi SiLPA terendah dan tertinggi denganpengumpulan data secara retrospektif. Hasil penelitian menunjukkan bahwa penggunaan dana kapitasi untuk jasa pelayanan telah sesuai target (69,5\%) sedangkan untuk kegiatan operasional penyerapan masih kecil (12,4 \%). Puskesmas belum melaksanakan perencanaan sistematis dengan tahapan Planning, Organizing, Actuating, Controlling dalam pemanfaatan dana kapitasi. Aturan pemanfaatan yang dianggap rumit menyebabkan puskesmas tidak menyerap dana kapitasi tersebut. Pengawasan dan bimbingan diperlukan agar penyerapan dana kapitasi dapat ditingkatkan.

Kata kunci : Pemanfaatan; Dana Kapitasi; Puskesmas
\end{abstract}

\begin{abstract}
Since the implementationof National Health Insurance (JKN), Health Centers received the payment from Social Security Agency for Health (BPJS) using capitation. In Lubuklinggau City, there has been problem inutilizing capitation and financing surplus (SiLPA) for approximately 23\% per year. This research aimed to analyze the utilization of capitationin Lubuklinggau City 2014-2016. This qualitative study was implemented in SimpangPeriuk Health Center, Taba, Citra Medika and Swasti Saba which werethe lowest and highest SiLPA absorption, and data were collected retrospectively. The study revealedthat the capitation funds have achieved the target (69,5\%) while spending for operational was still under utilized (12,4\%). The planning for using capitation funds was not systematically implemented using appropriate steps : Planning, Organazing, Actuating, Controlling. Health centers assumed thatthe regulationto use the funds was too complicated to follow so they could not absorp the capitation appropriately. Monitoring assitance are needed to improve the absorption of capitation funds. Keywords: Utilization; Capitation; Primary Health Care
\end{abstract}

\section{Pendahuluan}

Kesehatan merupakan hak asasi manusia. Declaration of Human Right menyatakan bahwa perawatan kesehatan dan pelayanan sosial merupakan hak asasi manusia yang paling dasar dan diakui oleh seluruh bangsa di dunia. Negara Indonesia telah melindungi setiap warga negaranya dengan dikeluarkannya Undang-Undang tentang Kesehatan.

Sejak 1 Januari 2014 Pemerintah melaksanakan Sistem Jaminan Kesehatan Nasional yang diselenggarakan oleh Badan Penyelenggara Jaminan Sosial (BPJS) Kesehatan. Pelayanan Kesehatan ke paserta JKN dilakukan oleh Fasilitas Kesehatan Tingkat Pertama (FKTP), salah satunya Puskesmas. BPJS Kesehatan melakukan pembayaran dengan sistem kapitasi yaitu berdasarkan jumlah peserta yang terdaftar di Puskesmas tanpa memperhitungkan jenis dan jumlah pelayanan kesehatan yang diberikan.

Menurut Perpres No. 32 tahun 2014, dijelaskan untuk pengelolaan dan pemanfaatan dana kapitasi adalah sekurang-kurangnya $60 \%$ untuk pembayaran jasa dan $40 \%$ untuk layanan operasional.

Dana kapitasi untuk pelayanan jasa dipergunakan untuk pembayaran jasa pelayanan kesehatan (tenaga kesehatan dan tenaga non kesehatan) sedangkan layanan operasional dialokasikan untuk alat kesehatan, obat, bahan habis pakai dan kegiatan operasional pelayanan kesehatan lainnya. Pemanfaatan dana kapitasi di Puskesmas pada setiap daerah berbeda-beda. Sebagai contoh, penyerapan kapitasi di daerah Karanganyar memiliki danasebesar Rp 6 milyar masih tersisa dari dana kapitasi (Rudi, 2016), sedangkan daerah Karawang memiliki sisa sebesar Rp 18 milyar (Raka, 2016). Besarnya sisa dana kapitasi memperlihatkan belum optimalnya pemanfaatan dana 
tersebut. Hal ini mengindikasikan bahwa ada hal-hal yang belum dimengerti atau ada peraturan -peraturan yang tidak sesuai dengan sistem pelaksanaan dilapangan.

Rachmi (2014) menyatakan bahwa masih terdapat Puskesmas di DKI Jakarta yang belum memanfaatkan dana kapitasi BPJS Kesehatan. Pemanfaatan dana kapitasi untuk operasional puskesmas dan upaya promotif dan preventif dianggap belum optimal sehingga perlu dievaluasi. Penelitian tentang evaluasi pemanfaatan dana kapitasi puskesmas di Kabupaten Seluma Provinsi Bengkulu menghasilkan belum optimalnya pemanfaatan dana kapitasi dikarenakan proses perencanaan yang belum dilakukan dengan baik dan belum berdasarkan prioritas masalah (Heriawan, 2015). Pemanfaatan dana kapitasi di Puskesmas tersebut belum optimal dikarenakan adanya perubahan pengalokasian yaitu jasa pelayanan (sebesar 60\%) dan dukungan operasional (sebesar 40\%) yang ditetapkan dalam Permenkes nomor 19 tahun 2014 (Anggraeni, 2016). Kurang optimalnya penyerapan dana kapitasi ini mengakibatkan sisa anggaran pada akhir tahun akan bertumpuk.

Laporan evaluasi Dinas kesehatan Kota Lubuklinggau tahun 2014-2016 program kemitraan peningkatan pelayanan kesehatan menunjukkan permasalahan pada sisa dana kapitasi Puskesmas yang cenderung menumpuk dengan total cukup besar yaitu Rp 1,4 milyar. Studi ini bertujuan untuk menganalisis pemanfaatan dana kapitasi berdasarkan peruntukan dana kapitasi dan kesesuaiannya dengan target capaian yang telah ditentukan dalam perencanaan kegiatan oleh Puskesmas pada Dinas Kesehatan Kota Lubuklinggau tahun 2014-2016.

\section{Metodologi Penelitian}

Penelitian ini menggunakan pendekatan kualitatif dengan pengumpulan data secara retrospektif. Penetuan sampel berdasarkan realisasi sisa dana kapitasi terbesar dan terkecil. Data primer diperoleh secara langsung dari informan melalui wawancara mendalam dengan menggunakan pedoman wawancara dan alat bantu perekam dan obeservasi mengenai sarana dan prasarana yang di Puskesmas berdasarkan daftar tilik. Data sekunder diperoleh melalui telaah data terkait pemanfaatan dana kapitasi Puskesmas. Setelah data terkumpul, field note dikembangkan, kemudian membuat transkrip data, mengkategorikan data dengan melakukan coding, meringkas dan menginterprestasikan. Pengecakan keabsahan data dilakukan dengan triangulasi sumber dan metode.

\section{Hasil Penelitian}

Pembangunan kesehatan bertujuan untuk meningkatkan kesadaran, kemauan, dan kemampuan hidup sehat bagi setiap orang agar terwujud derajat kesehatan masyarakat yang setinggi-tingginya. Dinas Kesehatan Kota Lubuklinggau dalam memenuhi peningkatan kesehatan dibantu oleh 9 Puskesmas yang berada di wilyahnya. Penelitian dilakukan di 4 Puskesmas berdasarkan realisasi sisa dana kapitasi yang digunakan.

Berdasarkan Peraturan Walikota dengan Keputusan Walikota Lubuklinggau nomor : 200/ KPTS/ KES/ 2014, alokasi dana kapitasi tahun 2014 untuk pembayaran jasa pelayanan kesehatan pada Puskesmas Kota Lubuklinggau ditetapkan sebesar 60\% sedangkan untuk alokasi dana kapitasi Puskesmas dukungan biaya operasional pelayanan kesehatan sebesar $40 \%$. Tabel 1 menjelaskan realisasi penggunaan dana kapitasi di empat Puskesmas tahun 2014 sebesar Rp 767.820.190,00 (74,67\%) sedangkan sisa dana kapitasi yang terjadi sebesar Rp 260.480.622,00 (25,33\%). Sisa dana kapitasi tersebut akan menjadi saldo pada awal tahun 2015 di rekening masing-masing Puskesmas untuk dana Jaminan Kesehatan Nasional (JKN).

Pada tahun 2015, berdasarkan Peraturan Walikota dengan Keputusan Walikota Lubuklinggau nomor: 6 /KPTS/KES/ 2015 ditetapkan alokasi penggunaan dana kapitasi Puskesmas pada Pelayanan jasa dan dukungan operasional yaitu $60 \%$ pada pelayanan jasa dan $40 \%$ pada dukungan operasional. Sisa dana kapitasi sebesar 19,59\% atau sejumlah $\mathrm{Rp}$ 393.105.842,00 untuk total ke emapat Puskesmas. Sisa dana kapitasi ini akan menjadi saldo pada awal tahun 2016 di rekening masing-masing Puskesmas untuk dana kapitasi (Tabel 2).

Dari tabel 3, sisa dana di tahun terakhir 2016 adalah Rp. 593.478.879,85. Dana sebesar ini jika dibiarkan akan bertumpuk karena terlihat dari setiap tahun berjalan, pemanfaatan dana kapitasi kurang maksimal sehingga tidak dapat membawa manfaat bagi masyarakat khususnya bagi orang-orang yang membutuhkan pelayanan kesehatan. Dengan demikian peneliti melihat bagaimana pemanfaatan dana kapitasi puskesmas berdasarkan sumber daya di puskesmas dan sumber-sumber dana lain yang menjadi pendukung kegiatan di puskesmas.

\section{Pembahasan}

Pada tabel realisasi tahun 2016, peneliti melihat akumulasi dana kapitasi yang tersisa dari tahun 2014 sampai dengan 2016 mencapai angka yang 
Tabel 1. Realisasi Anggaran Dana Kapitasi Puskesmas Dinas Kesehatan Kota Lubuklinggau Tahun 2014

\begin{tabular}{|c|c|c|c|c|}
\hline \multirow{3}{*}{ No } & \multirow{3}{*}{ Puskesmas } & \multicolumn{3}{|c|}{ Tahun 2014} \\
\hline & & Perolehan & Penggunaan & $\begin{array}{c}\text { SisaAnggaran (Menjadi } \\
\text { Saldo di Tahun Berikut- } \\
\text { nya) }\end{array}$ \\
\hline & & $\mathbf{R p}$ & $\mathbf{R p}$ & $\mathbf{R p}$ \\
\hline 1. & Simpang Periuk & $340.699 .833,00$ & $\begin{array}{c}257.649 .700,00 \\
(75,62 \%)\end{array}$ & $\begin{array}{c}83.050 .133,00 \\
(24,38 \%)\end{array}$ \\
\hline 2. & Taba & $401.390 .333,00$ & $\begin{array}{c}306.811 .950,00 \\
(76,44 \%)\end{array}$ & $\begin{array}{c}94.578 .383,00 \\
(23,56 \%)\end{array}$ \\
\hline 3. & Citra Medika & $167.621 .333,00$ & $\begin{array}{c}125.367 .460,00 \\
(74,79 \%)\end{array}$ & $\begin{array}{c}42.253 .873,00 \\
(25,21 \%)\end{array}$ \\
\hline 4. & Swasti Saba & $118.589 .333,00$ & $\begin{array}{c}77.991 .080,00 \\
(65,77 \%)\end{array}$ & $\begin{array}{c}40.598 .253,00 \\
(34,23 \%)\end{array}$ \\
\hline & Total & $\begin{array}{c}1.028 .300 .832,00 \\
(74,67 \%)\end{array}$ & $\begin{array}{c}767.820 .190,00 \\
(25,33 \%)\end{array}$ & $260.480 .622,00$ \\
\hline
\end{tabular}

Tabel 2. Realisasi Anggaran Dana Kapitasi Puskesmas Dinas Kesehatan Kota Lubuklinggau Tahun 2015

\begin{tabular}{|c|c|c|c|c|c|}
\hline \multirow{3}{*}{ No } & \multirow{3}{*}{ Puskesmas } & \multicolumn{4}{|c|}{ Tahun 2015} \\
\hline & & $\begin{array}{c}\text { SaldoAwal (Sisa } \\
\text { Anggaran Tahun } \\
\text { 2014) }\end{array}$ & Perolehan & Penggunaan & $\begin{array}{l}\text { SisaAnggaran } \\
\text { (menjadi saldo di- } \\
\text { tahun berikutnya) }\end{array}$ \\
\hline & & Rp & Rp & $\mathbf{R p}$ & Rp \\
\hline 1. & Simpang Periuk & $83.050 .133,00$ & $548.717 .500,00$ & $\begin{array}{c}478.241 .060,00 \\
(75,70 \%)\end{array}$ & $\begin{array}{c}153.526 .573,00 \\
(24,30 \%)\end{array}$ \\
\hline 2. & Taba & $94.578 .383,00$ & $648.141 .000,00$ & $\begin{array}{c}605.049 .650,00 \\
(81,46 \%)\end{array}$ & $\begin{array}{c}137.669 .733,00 \\
(18,54 \%)\end{array}$ \\
\hline 3. & Citra Medika & $42.253 .873,00$ & $368.387 .500,00$ & $\begin{array}{c}324.962 .400,00 \\
(79,13 \%)\end{array}$ & $\begin{array}{c}85.678 .973,00 \\
(20,87 \%)\end{array}$ \\
\hline 4. & Swasti Saba & $40.598 .253,00$ & $181.902 .000,00$ & $\begin{array}{c}206.269 .690,00 \\
(92,71 \%)\end{array}$ & $\begin{array}{c}16.230 .563,00 \\
(7,29 \%)\end{array}$ \\
\hline & Total & $260.480 .622,00$ & $\begin{array}{c}1.747 .148 .000 \\
(80,41 \%)\end{array}$ & $\begin{array}{c}1.614 .522 .800,00 \\
(19,59 \%)\end{array}$ & $393.105 .842,00$ \\
\hline
\end{tabular}

cukup besar yaitu Rp 593.478.879,85 (24,45\% dari total dana kapitasi yang di dapat dalam 3 tahun terakhir). Realisasi anggaran pada tahun terakhir yaitu sebesar Rp1.883.179.531.30 (75,53\%). Jika dilihat dari setiap tahun anggaran berjalan, Puskesmas ti- dak mengalami peningkatan persentase yang signifikan dalam realisasinya yaitu dalam kisaran $75 \%$. Sedangkan untuk dana kapitasi yang tersisa dalam tiap tahun berjalannya berkisar 24\%. Padahal pada tahun 2016,berdasarkan PeraturanWalikota den- 
Tabel 3 Realisasi Anggaran Dana Kapitasi Puskesmas Dinas Kesehatan Kota Lubuklinggau Tahun 2016

\begin{tabular}{|c|c|c|c|c|c|}
\hline \multirow{3}{*}{ No } & \multirow{3}{*}{ Puskesmas } & \multicolumn{4}{|c|}{ Tahun 2016} \\
\hline & & $\begin{array}{c}\text { SaldoAwal } \\
\text { (Sisa Anggaran } \\
\text { Tahun 2015) }\end{array}$ & Perolehan & Penggunaan & $\begin{array}{c}\text { Sisa Anggaran } \\
\text { (menjadi saldo } \\
\text { ditahun berikut- } \\
\text { nya) }\end{array}$ \\
\hline & & $\mathbf{R p}$ & Rp & $\mathbf{R p}$ & $\mathbf{R p}$ \\
\hline 1. & SimpangPeriuk & $153.526 .573,00$ & $599.910 .000,00$ & $\begin{array}{c}529.945 .295,00 \\
(70,33 \%)\end{array}$ & $\begin{array}{c}223.491 .278,00 \\
(29,67 \%)\end{array}$ \\
\hline 2. & Taba & $137.669 .733,00$ & $656.136 .000,00$ & $\begin{array}{c}532.987 .508,00 \\
(67,1 \%)\end{array}$ & $\begin{array}{c}260.818 .225,00 \\
(32,9 \%)\end{array}$ \\
\hline 3. & Citra Medika & $85.678 .973,00$ & $557.010 .000,00$ & $\begin{array}{c}550.002 .074,15 \\
(85,58 \%)\end{array}$ & $\begin{array}{c}92.686 .898,85 \\
(14,42 \%)\end{array}$ \\
\hline 4. & Swasti Saba & $16.230 .563,00$ & $220.617 .500,00$ & $\begin{array}{c}220.365 .585,00 \\
(93,04 \%)\end{array}$ & $\begin{array}{c}16.482 .478,00 \\
(6,94 \%)\end{array}$ \\
\hline & Total & $393.105 .842,00$ & $\begin{array}{c}2.033 .673 .500,00 \\
(75,53 \%)\end{array}$ & $\begin{array}{c}1.833 .179 .531,30 \\
(24,45 \%)\end{array}$ & $593.478 .879,85$ \\
\hline
\end{tabular}

gan Keputusan Walikota Lubuklinggau nomor: 71/ KPTS/ KES/ 2016, alokasi dana kapitasi untuk pelayanan jasa telah diperbesar menjadi sebesar 75\% dan dukungan operasional sebesar $25 \%$.

\section{Sumber Daya}

Dalam kaitan dengan pemanfaatan dana kapitasi hampir seluruh Informan menyatakan bahwa sumber daya manusia sangat erat sekali kaitannya dengan pemanfaatan dana kapitasi. Karena di dalam Permenkes No. 21 tahun 2016, salah satu item yang diperbolehkan dalam penyerapan dana kapitasi itu adalah untuk Jasa Pelayanan.

Proses pelayanan puskesmas sangat dipengaruhi oleh ketersediaan dan kepatuhan pada standar pelayanan perilaku tenaga kesehatan yang melayani, kecukupan suplai obat-obatan dan alat kesehatan. Informan di Dinas Kesehatan menyatakan bahwa semakin baik dan loyal pelayanan SDM yang ada di Puskesmas dalam hal tenaga dokter, hal ini akan meningkatkan minat orang-orang (pasien) yang akan berkunjung ke Puskesmas tersebut.

Sumber Daya pada penelitian ini yaitu Sumber Daya Manusia (SDM), sarana dan prasaran yang dipergunakan Puskesmas dalam aktivitas pelayanan. Sumber daya manusia (SDM) yang berada di Puskesmas meliputi tenaga medis,paramedis dan tenaga non medis. Sumber Daya Manusia pada 4 Puskesmas sudah tercukupi dari segi jenis tenaga untuk Puskesmas Simpang Priuk, masih kekurangan 3 tenaga dokter dan 1 dokter gigi.
Sarana dan prasarana merupakan salah satu penunjang dalam suatu kegiatan. Tanpa adanya dukungan dari sarana dan prasarana, pelaksanaan pelayanan terhadap pasien tidak dapat terlaksana dengan baik. Dari keempat Puskesmas yang menjadi wilayah penelitian, hanya Puskesmas Simpang periuk yang memiliki layanan 24 jam dan rawat inap. Secara umum, kelengkapan sarana dan prasarana keempat Puskesmas sudah baik. Puskesmas Swasti Saba telah memiliki gedung dan ruangan untuk layanan 24 jam dan rawat inap, namun pelayanan belum dilakukan dikarenakan kelengkapan dari sarana dan prasarana berupa alat kesehatan dan penunjang lainnya belum terpenuhi dengan maksimal.

\section{Sumber Dana}

Setiap instansi Pemerintahan mendapatkan dana dari berbagai macam sumber. Puskesmas mendapat dana daridari APBD, APBN dan sumber dana lain. Dalam penelitian ini Puskesmas di Kota Lubuklinggau mendapatkan dana dari APBD, APBN (BOK) dan Dana Kapitasi (JKN). Pada kegiatan operasional, Puskesmas mendapatkan sumber dana dariAPBN dan Dana Kapitasi JKN. Pendapat ini sesuai dengan hasil wawancara terhadap informan Puskesmas, bahwa sebagian besar Puskesmas menggunakan kedua dana tersebut untuk kegiatan operasional. Sebagian besar informan Puskesmas juga mengatakan bahwa dana kapitasi menjadi sumber dana utama. Dana APBD lebih fokus kepada kegiatan fisik seperti pembangunan gedung, pembelian alat-alat kesehatan dan 
obat-obat. Karena itulah Puskesmas lebih memanfaatkan dana kapitasi untuk kegiatan-kegiatan di Puskesmas.

\section{Perencanaan}

Puskemas tiap tahunnya memiliki perencanaan untuk kegiatan selama 1 periode yang disusun pada setiap akhir tahun berjalan. Khususuntuk perencanaan yang berkaitan dengan dana kapitasi ini, hal ini meliputi kegiatan-kegiatan pelayanan, pembelian alat kesehatan dan obat-obatan serta kegiatan operasional yang mendukung berjalannya pelayanan kesehatan di Puskesmas. Proses perencanaan Puskesmas untuk dana kapitasi dapat digambarkan dalam diagram 1. Kendala di dalam perencaanaan adalah adanya perubahan anggaran, yang biasa terjadi di pertengahan tahun. Ini dapat mengakibatkan perencaanan yang semulanya telah matang disusun mengalami perubahan nilai nominal atau bahkan pengurangan yang tidak signifikan. Hal inilah yang mengakibatkan sisa dana kapitasi Puskesmas bisa terjadi. Peneliti mengusulkan, sebaiknya, diawal trimester pertama Puskesmas merencanakan kegiatan yang menjadi prioritas utama, yaitu kegiatan yang memiliki manfaat lebih banyak untuk pasien dan perbaikan pelayanan di Puskesmas. Selain itu Puskesmas juga harus memiliki check list sederhana kebutuhan alat kesehatan atau barang sehingga tidak diperlukan waktu yang lama dalam persetujuan pengajuan kebutuhan tersebut.

\section{Pengorganisasian dan Pelaksanaan}

Pelaksanaan merupakan rangkaian kegiatan fungsi manajemen dalam mencapai tujuan suatu organisasi. Peran pemimpin merupakan hal yang penting dalam tahap pengorganisasian dan pelaksanaan ini. Kepemimpinan adalah kemampuan untuk mempengaruhi aktivitas seseorang atau sekelompok orang untuk mencapai suatu tujuan yang telah ditetapkan dalam suatu situasi tertentu. Secara umum kemampuan manajerial pimpinan seluruh Puskesmas sudah sangat baik dengan gaya kepemimpinan yang berbeda-beda dari setiap pimpinan.

Hasil penelitian didapatkan yaitu: (1) kepala Puskesmas dan bendahara JKN telah memahani dengan baik aturan tentang pemanfaatan dana kapitasi Puskesmas; (2) pada awal JKN terbentuk, Puskesmas mengalami beberapa kendala dan kebingungan, karena pada tahun 2014, banyak sekali regulasi yang berubahdalam waktusangat singkat, namun kepala puskesmas berusaha untuk cepat untuk beradaptasi dengan perubahan peraturan tersebut; (3) mekanisme pemberian perintah terhadap staf dan koordinasi dengan pihak Dinas Kesehatan telah dijalankan dengan baik, bahkan ada satu Puskesmas yaitu Swasti saba, yang selalu intens dalam melaksanankan rapat untuk kemaksaimal pemanfaatan dana kapitasi di puskesmas.

Jika dilihat dari ketiga point diatas, makahal tersebut harus dipertahankan dengan baik. Koordinasi antara pihak dinas kesehatan dan puskesmas, puskesmas dan stakeholder serta feedback dengan para staf di puskesmas harus sejalan dengan tujuan atau perencanaan pemanfaatan dana kapitasi ini.

\section{Pengawasan}

Pengawasan merupakan bentuk pengendalian dalam proses pengamatan yang secara terus - menerus dilakukan dengan menetapkan ukuran tertentu yang selanjutnya akan diadakan pengoreksian terhadap penyimpangan-penyimpangan yang terjadi. Dinas kesehatan telah rutin (satu bulan sekali) melakukan koordinasi kepada Puskesmas. Bentuk pengawasan dilakukan dengan pemanggilan ke dinas kesehatan

Diagram 1. Proses Perencanaan Puskesmas

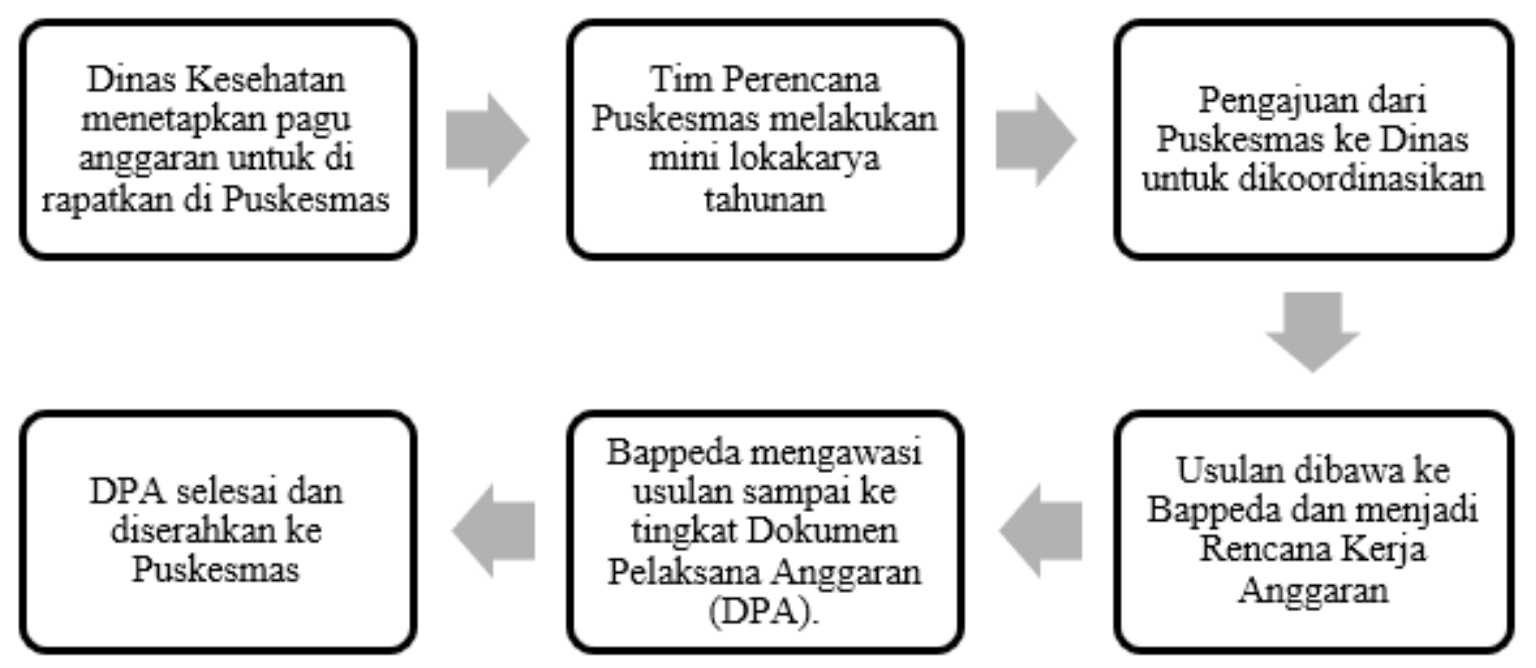


atau mengunjungi puskesmas secara langsung.

Pihak BPJS Kesehatan melakukan bentuk pengawasan yang terfokus pada pelayanan Puskesmas bukan pada pemanfaatan dana kapitasi. Alasan dari pihak BPJS dikarenakan BPJS tidak memiliki tupoksi untuk mengawasi dan mengcroschek secara rinci keuangan Puskesmas khususnya pemanfaatan dana kapitasi yang dikeluarkan Puskesmas.

Untuk Inspektorat memilki wewenang dan mengevaluasi dalam bentuk keuangan. Inspektorat dapat melakukan pengecekan terhadap kuitansi dan bukti belanja yang dibeli terhadap barang-barang yang diperlukan. Pengawasan tidak dilakukan pada pemeriksaan pemanfaatan dana kapitasi Puskesmas, atau sampai melakukan punishment terhadap Puskesmas yang tidak melaksanakan aturan mengenai dana kapitasi. Inspektorat beralasan karena JKN ini merupakan dana pusat.

Untuk Bappeda hanya melakukan pengawasan dari bentuk rencana kerja yang diusulkan dari Dinas kesehatan sampai bentuk rencana kerja anggaran. Pembahasan rencana kerja dilakukan oleh tim pemerintah kota untuk dilanjutkan dalam bentuk DPA. Jadi untuk melakukan pengawasan terhadap bagaimana pemanfaatan dana kapitasi ini dikerjakan bukan wewenang dan tupoksi dari Bappeda.

\section{Regulasi}

Berdasarkan hasil observasi dan wawancara, sampai saat ini pelaksaan program JKN dan pemanfaatan dana kapitasi tahun 2014-2016 ke empat Puskesmas yang menjadi objek penelitian sudah menjalankan atauran dengan sebagaimana mestinya. Peraturaan yang sudah ada sesuai dengan kebutuhan dalam pengelolaan dana kapitasi di Puskesmas. Regulasi yang dibuat oleh pemerintah Pusat dan daerah sudah dapat menjadi pedoman Puskesmas untuk melakukan serangkaian kegiatan dalam pemanfaatan, penatausahaan dan pertanggungjawaban dana kapitasi JKN.

Ada beberapa hal terkait dengan masalah dalam pelaksanaannya dilapangan yaitu: (1) terlalu luasnya bidang program dengan sifat tujuan yang kompleks yang dijalankan oleh Puskesmas; (2) akibat dari ketidakjelasan dan kontradiksi dalam pernyataan ukuran-ukuran (peraturan) dasar dan tujuantujuan; (3) mengenai perubahan anggaran biaya tambahan yang ketok palunya atau persetujuannya mendekati limit diakhir akhir, yang menyebabkan Pihak Puskesmas jadi ragu dalam melaksanakan pencairan dana kapitasi; (4) lambatnya sosialisasi peraturan-peraturan terbaru mengenai pemanfaatan dana kapitasi yang puskesmas baru mendengarnya atau mengetahui di pertengahan tahun. Dari permasalahan tersebut, solusi yang dapat dilakukan adalah adanya komunikasi dan koordinasi yang lebih intens antara Dinas Kesehatan, Puskesmas, BPJS Kesehatan, dan instansi terkait yang berhak melakukan pengawasan tentang dana kapitasi ini.

\section{Capaian Pemanfaatan Dana Kapitasi Puskesmas}

Capaian dari pemanfaatan ini merupakan koordinasi antara pelaksanaan pengorganisasi kepemimpinan Puskesmas dengan pengawasan yang dilakukan. Dengan demikian apa yang direncanakan dalam sebuah DPA akan terlaksana dengan baik. Capaian ini merupakan target dari perencanaan yang telah diatur dalam permenkes nomor 21 tahun 2016 dan juga peraturan walikota yang setiap tahunnya dikeluarkan oleh Pemerintah Kota Lubuklinggau.

Dari hasil observasi dan wawancara dengan ke empat Puskesmas tersebut terlihat belum maksimalnya yang dicapai dalam persentase baik dalam jasa pelayanan maupun dukungan operasional. Untuk tahun 2014 dan 2015, realisasi capaian pemanfaatn dana kapitasi masih menyisakan dana yang cukup besar. Target capaian pada tahun 2014 yang belum maksimal yaitu $74 \%$ bisa disebabkan oleh beberapa hal diantaranya pertama, tahun 2014 merupakan awal tahun bagi permulaan bangsa Indonesia melakukan pembayaran langsung kepada Puskesmas melalui via rekening Puskesmas, adaptasi terhadap pelakasanaan peraturan pun diperlukan untuk itu, penyebab kedua adalah banyak perubahan-perubahan regulasi tentang pemanfaatan dana kapitasi ini.

Adanya 2 kali peraturan yang berubah pada saat ditahun 2014 tersebut, yaitu pertama Peraturan Walikota Lubuklinggau nomor : 46 /KPTS/KES/2014 tentang penetapan pengelolaan dana pelayanan kesehatan pada program Jaminan Kesehatan Nasional di Pelayanan tingkat pertama kota lubuklinggau dengan tanggal penetapan 8 Januari 2014, kedua peraturan walikota Lubuklinggau nomor 200/ KPTS/ KES/2014 tentang alokasi dana kapitasi jaminan kesehatan nasional pada Puskesmas dengan tanggal penetapan 28 Mei 2014.

Untuk tahun 2015, pemanfaatan dana kapitasi semakin menurun, itu disebabkan oleh adanya anggaran perubahan di daerah. Biasanya perubahan ini tidak serta merta yang berubah yang dibutuhkan saja, tetapi ketika itu ada perubahan maka mekanisme yang lama bisa berubah juga. Ditambah lagi pada saat penetapan di DPRD kota Lubuklinggau, dilaksanakan pada saat menjekang akhir tahun 2015. Oleh sebab itu, hampir seluruh Puskesmas di Kota Lubuklinggau tidak melakukan pencairan dana 
pada saat itu dikarenakan waktu yang tidak mungkin dilaksanakan dalam mekanisme keuangan daerah.

Pada saat penetapan di tahun 2014 dan tahun 2015 itu, alokasi jasa dan biaya oparasionalnya sebesar $60 \%$ untuk jasa pelayanan dan $40 \%$ untuk biaya operasional. Pada tahun 2016, melihat sisa dana kapitasi yang cukup besar di dua tahun sebelumnya maka pihak dinas kesehatan disertai dengan rapat sebelumnya dengan seluruh puskesmas mengajukan usul kepada walikota untuk perubahan alokasi persentase jasa dan biaya operasional yang semulanya sebesar $60 \%$ menjadi $75 \%$ untuk jasa pelayanan. Jasa pelayanan alokasi berubah dari $40 \%$ menjadi 25 $\%$. Keputusan dibuat dalam surat keputusan walikota nomor 71/KPTS/KES/2016 tentang alokasi dana kapitasi jaminan kesehatan nasional pada Puskesmas.

Di tahun 2016, pencapaian realisasi pemanfaatan dana kapitasi tidak terlalu signifikan. Puskesmas Taba mengalami penurunan sementara Puskesmas Swasti Sabamengalami perubahan yang sangat signifikan. Tetapi seluruh puskesmas masih memiliki sisa dana kapitasi yang belum termanfaatkan terutama pada dukungan operasional. Ada pun penyebab minimnya pencapaian pada sisi operasional yaitu terjadinya perubahan harga pasar. Nilai harga pasar lebih tinggi dari pada nilai standar satuan harga dinas terhadap barang-barang yang akan dibeli. Dengan demikian hampir seluruh Puskesmas tidak bisa membelanjakan dana kapitasinya untuk pembelian baik itu obat, alat-alat kesehatan dan BHP. Hanya sebagian kecil saja yang bisa dibelanjakan untuk kebutuhan Puskesmas.

\section{Kesimpulan dan Saran \\ Kesimpulan}

Penggunaan dana kapitasi Puskesmas di Kota Lubuklinggau sudah sesuai dengan penggunaannya tetapi dalam hal pencapaian realisasi dana kapitasi masih belum maksimal terutama di penggunaan biaya operasional. Sisa dana kapitasi puskesmas sebagian besar berasal dari sisa dukungan operasional, bukan berasal dari sisa jasa pelayanan. Rencana kerja anggaran dan kepemimpinan berkaitan langsung dengan pemanfaatan dana kapitasi Puskesmas. Sumber daya manusia, sumber dana, sarana dan prasarana serta proses pengawasan tidak berkaitan secara langsung dengan pemanfaatan dana kapitasi.

\section{Saran}

Puskesmas seharusnya membuat sistem kerja POAC (Planning, Organizing, Actuating, Controling) sebagai schedule tetap tahunan yang berfokus pada dana kapitasi dan harus fokus kepada biaya operasional dana kapitasi dengan membuat rencana kerja yang matang, karena dilihat dari evaluasi tiga tahun terakhir, pencapaian biaya operasional masih minim realisasi. Dinas Kesehatan, BPJS Kesehatan dan Inspektorat, beserta seluruh kepala puskesmas perlu duduk bersama dalam mencari solusi untuk pemanfaatan sisa dana kapitasi puskesmas dalam tiga tahun terakhir yang mencapai angka 1,4 milyar rupiah.

\section{Daftar Pustaka}

Anggraeni dkk.2016. Analisis Pemanfaatan Dana Kapitasi Oleh Puskesmas Dalam Penyelengaraan Jaminan Kesehatan Nasional Di Kabupaten Purbalingga. Jurnal : Bagian Administrasi dan Kebijakan Kesehatan Fakultas Kesehatan Masyarkaat Universitas Diponegoro Provinsi Sumatera.

Heriawan. 2015. Evaluasi Pemanfaatan Dana Kapitasi Jaminan Kesehatan Nasional Di Puskesmas Kabupaten Seluma Propinsi Bengkulu. Tesis. Yogyakarta : Program Pascasarjana Fakultas Kedokteran Universitas Gadjah Mada.

Kemenkesa. 2014.Peraturan Presiden Nomor 32 Tahun 2014 Tentang Pengelolaan Dan Pemnfaatan Dana Kapitasi Jaminan Kesehatan Nasional Pada Fasilitas Kesehatan Tingkat Pertama Milik Pemerintah Daerah.

Kemenkesb. 2014. Peraturan Menteri Kesehatan Republik Indonesia Nomor 19 Tahun 2014 Tentang Penggunaan Dana Kapitasi Jaminan Kesehatan Nasioanl Untuk Jsa Pelayanan Kesehatan dan Dukungan Biaya Operasional Pada Fasilitasi Kesehatan Tingkat Pertama Milik Pemerintah Daerah.

Rachmi, Eliza. 2014. Implementasi Jaminan Kesehatan Nasioanal Dalam Pemanfaatan Dana Kapitasi Pada Puskesmas Yang Menerapkan Pola Pengelolaan Keuangan Badan Layanan Umum Daerah Di Provinsi DKI Jakarta. Tesis. Depok. Fakultas Kesehatan Masyarakat Universitas Indonesia.

Rudi, Hartono. 2016. JogloSemar.co. Dana Kapitasi Rp 6 Milyar Nganggur. 29 Februari 2016. $<$ http://dok.joglosemar.co/baca/2016/02/29/dana-kapitasi-rp-6-m-nganggur.html>

Raka. 2016. radar-karawang.com. Usut Dana Kapitas̄i. 2 November 2016. <http://www.radar-karawang.com/2016/11/usut-dana-kapitasi.htm$1 ? \mathrm{~m}=0>$

Universal Declaration of Human Right. http://www. ohchr.org/EN/UDHR/Documents/UDHR_Translations/eng.pdf 